\title{
El proceso civil como vía para reducir divergencias entre las partes
}

\section{The civil process as a means to reduce the differences between the parties}

\author{
Nicolás Ignacio Ariel Carrasco Delgado \\ Universidad de Chile \\ ncarrascod@gmail.com
}

Recibido: 11/05/18 | Aceptado: 31/10/18

RESUMEN: Desde el análisis económico del derecho se aborda una característica del proceso que ayuda a un juez a resolver un conflicto civil con el uso de criterios de eficiencia. Misma que corresponde a la posibilidad de que las reglas procesales permitan reducir las divergencias entre las partes. Una posibilidad que no ha sido explorada por la doctrina, debido a que el proceso civil es enfocado como un ámbito de decisión no colaborativo. Por esta razón, se sostiene que el proceso es un juego, en donde las partes y el juez cumplen diversos roles condicionados por las normas procesales. El cual debe fomentar que las posiciones de las partes se expresen de manera sincera y definitiva.

PALABRAS CLAVE: análisis económico del derecho, derecho procesal, criterios de eficiencia.

\begin{abstract}
From economic analysis of law, I deal a procedural characteristic that help at judge to resolve a civil conflict with efficiency criteria. These characteristic imply that the procedural rules allow to reduce the differences between the parties. One possibility that has not been explored by the doctrine, because the civil procedural is focused how a context without collaborative. For this reason, I put forth that the procedure is a game where the parties and judge comply different roles, the according to the procedural rules. The process must foment that the parties claims be formulate in a honest and definitive way.
\end{abstract}

KEY WORDS: economic analysis of law, civil procedural law, efficiency criteria. 


\section{SUMARIO}

I. El proceso civil como juego único. II. El juicio único procesal como vía para reducir divergencias entre las partes. II.1 Juego cooperativo finito sin reglas (cooperar o apropiar). II.2. Juego procesal único con reglas (juicio de reivindicación). II.3 El ejemplo del juicio verbal en el Derecho procesal civil español. III. Conclusiones. Bibliografía.

\section{El proceso civil como juego único}

La investigación se centra en la característica del litigio como juego generalmente no repetitivo, esto es, como juego único; y para ello, es importante aclarar el concepto de juego procesal. Primero, definiremos el proceso corresponde a una actividad encaminada a un fin, en el que intervienen distintos sujetos. Se trata de un contexto de relación procesal (Marinoni, Pérez y Núñez, 2010, pp. 359364), donde cada parte tiene un rol y busca alcanzar una decisión, ya sea porque ejerce una función (juez), o bien, porque en el proceso se afectan sus intereses (partes). La idea del proceso como un juego ha sido cuestionada desde el Derecho procesal, negando que se pueda hablar de juego procesal o de alguna metáfora similar:

El proceso judicial, de hecho, no es asimilable a un juego. Entre las muchas razones por las que un proceso no puede considerarse un juego, la más importante de ellas es que los procesos no terminan como los juegos, las apuestas o las competiciones, ni siquiera como terminan los procesos electorales u otros tipos de pure procedural justice. Un juego contiene en sí mismo (es decir: en sus reglas de procedimiento), el mecanismo que predetermina su resultado: la fijación de límites de tiempo, las formas en que se asignan los puntajes, las maneras como se formulan y asignan los votos, el orden de llegada, el jaque mate, etc. En todos estos casos no se necesita de nada más que determina de quién es la victoria o la derrota [...] El proceso en cambio, no tiene en sí mismo -es decir, en las reglas de procedimientomecanismo alguno que predetermine su resultado aunque, obviamente, el desarrollo concreto y específico de todo proceso condiciona de varias maneras el contenido de la decisión final (Taruffo, 2007, pp. 27-28). 
Una conceptualización como ésta es equivocada, porque se compara el juego procesal con un juego cualquiera como el ajedrez, donde, por ejemplo, dadas ciertas situaciones y movimientos, se produce algo denominado jaque mate. En cambio, cuando se quiere decir que el proceso es un juego se pretende resaltar exclusivamente el carácter dirimente de las decisiones jurisdiccionales. Éstas se diferencian de las decisiones inmanentes, a las que se refiere la crítica mencionada, las cuales no alteran la estructura y las reglas del juego porque simplemente las aplican (por ejemplo, las reglas que determinan el efecto de jaque mate, cuando se producen determinados movimientos en el ajedrez). En oposición, las decisiones dirimentes son aquellas que reflejan la idea del Derecho como una actividad dinámica que se encuentra en creación constante, una de cuyas fuentes es precisamente el ejercicio jurisdiccional donde se crean normas jurídicas particulares (Sierraalta, 2010, pp. 379-380).

Entonces, si delimitamos el proceso en términos de creación de decisiones dirimentes no hay obstáculo alguno para considerarlo como un juego de aquellos que crean tales decisiones. Ello, con todo, deja a salvo lo obvio, referido a que el proceso es una convención reglada cuyas normas son conocidas ex ante por quienes allí participan (las partes y el juez). De esta forma, la concatenación de actos que configuran el proceso van encaminadas a una convención acabada de carácter heterónoma (sentencia).

Ahora bien, la oportunidad única comprende las instancias que existen dentro del juicio (primera y segunda instancia), esto es, distintos estados de conocimiento de los hechos y del Derecho por parte de diversos tribunales. De esta forma, la idea de oportunidad única o no repetitiva, se traduce en la idea de que, generalmente, en cada una de esas instancias las posibilidades de decidir se reducen a una única oportunidad. Ello bajo la suposición de que los jueces en cada instancia son distintos a los que conocieron el asunto en instancias anteriores ${ }^{1}$.

Así, la decisión adoptada en el juicio como un todo, al producir efectos

\footnotetext{
1 En España se regula como causal de abstención, y en su caso, de recusación, el hecho de «haber emitido dictamen sobre el pleito o causa como Letrado» (artículo $219 \mathrm{~N}^{\circ} 5$ de la Ley Orgánica 6/1985, de 1 de julio, del Poder Judicial), o, «haber fallado el pleito o causa en anterior instancia» (artículo 219 Nº 9 de la Ley Orgánica 6/1985, de 1 de julio, del Poder Judicial).
} 
de cosa juzgada sustancial determina que el juez resolverá ese asunto particular (aquel en el que concurren las identidades que señale la $l e y^{2}$ ) una sola vez. La decisión una vez firme y ejecutoriada ${ }^{3}$, adquiere el carácter de inmutable tanto dentro como para cualquier proceso posterior, y el asunto no podrá volver a plantearse. Existen una serie de instrumentos procesales tendentes a resguardar que ese efecto de cosa juzgada se preserve ${ }^{4}$. En esas consideraciones se basa la caracterización del proceso como un juego único y no repetido. La cosa juzgada sustancial le otorga ese carácter.

Junto con la cosa juzgada sustancial concurre la cosa juzgada formal. Según Eduardo Couture, la cosa juzgada formal corresponde al efecto de las resoluciones que «Se cumplen y son obligatorias tan sólo en relación al proceso en que se han dictado [...]» (Couture, 2004, p. 339).

La cosa juzgada formal corresponde a la cualidad de los efectos de una sentencia consistentes en su impugnabilidad dentro del proceso al haber operado la preclusión de los medios recursivos que pudieron interponerse en su contra. La cosa juzgada formal dice relación con la obligatoriedad que van adquiriendo determinadas resoluciones a lo largo del juicio5. Así, la cosa juzgada formal corresponde a un antecedente de la cosa juzgada sustancial. Al proceso entendido como una concatenación de actos hacia un fin determinado, le interesa ir cerrando

2 En el caso del Derecho procesal civil español, el efecto de cosa negativo de la cosa juzgada, se encuentra regulado en el artículo 222 de la Ley 1/2010, de 7 de enero, de Enjuiciamiento Civil.

3 En el caso del Derecho procesal civil español, producen cosa juzgada las resoluciones que tienen el carácter de firmes, adquiriendo tal carácter las resoluciones cuando no cabe recurso alguno en su contra ya sea porque no es previsto por la ley, o bien, porque estando previsto, ha transcurrido el plazo legalmente fijado sin que ninguna de las partes lo haya presentado (artículo $207 \mathrm{~N}^{\circ} 2,3$ y 4 de la Ley 1/2010, de 7 de enero, de Enjuiciamiento Civil).

4 En el sistema español el efecto de cosa juzgada se resguarda de acuerdo a ciertos instrumentos, entre ellos: (i) El carácter de invariabilidad de las resoluciones, el que se encuentra limitado a ciertas aclaraciones, correcciones, subsanaciones y complementos específicamente dispuestos por la ley (artículos 214 y 215 de la Ley 1/2010, de 7 de enero, de Enjuiciamiento Civil); (ii) Con el efecto de cosa juzgada negativa que impide la existencia de un proceso ulterior que posea identidad de objeto con el proceso en que el efecto de cosa juzgada se produjo (artículo 222 de la Ley 1/2010, de 7 de enero, de Enjuiciamiento Civil); (iii) Con la preclusión de la alegación de hechos y fundamentos jurídicos tratada en el artículo 400 de la Ley 1/2010, de 7 de enero, de Enjuiciamiento Civil, y (iv) Por medio de la consagración de la cosa juzgada y la litis pendencia como una cuestión procesal regulada en los artículos $416 \mathrm{~N}^{\circ} 2$ y 421 de la Ley 1/2010, de 7 de enero, de Enjuiciamiento Civil. 5 Así lo establece el artículo $207 \mathrm{~N}^{\circ} 3$ y 4 de la Ley 1/2010, de 7 de enero, de Enjuiciamiento Civil. 
las cuestiones accesorias que se van suscitando durante su tramitación, de la misma forma que le interesa que la cuestión principal no sea discutida nuevamente. En ambos casos se encuentra presente la idea del juego único.

La característica fundamental del proceso como juego no repetitivo es dar cuenta del hecho que el juez al momento de adoptar una decisión judicial posee una única oportunidad para resolver (asociado a cada instancia de decisión). Esa única oportunidad de decisión es una restricción institucional que impone el proceso al nivel de conocimiento que el juez tendrá de los hechos del asunto ${ }^{6}$.

Además, concurre otra restricción asociada a esa única oportunidad para poder decidir. La misma refiere el hecho que el juez no se encuentra facultado para decidir non liquet, declarando un asunto sin solución. La alternativa opuesta al not liquet, es el deber de inexcusabilidad que implica la necesidad ineludible del juez de resolver el asunto que conozca utilizando el sistema de fuentes (Martínez, 2012, pp. 113-118). El principio de inexcusabilidad, el cual se contempla en el sistema español en el artículo 1.7 del Código Civil ${ }^{7}$, ha sido considerado parte integrante de las reglas básicas que deben utilizar los jueces para generar certeza jurídica ${ }^{8}$.

Adicionalmente, el juez debe resolver porque ejerce una función pública judicial que impone la necesidad de decidir con efecto de cosa juzgada, a fin de otorgar seguridad jurídica y estabilidad a las normas jurídicas (Kremer, 2010, pp. 189-191). Así, Alexy señala que «La coerción es necesaria si el derecho pretende ser una práctica social que satisface sus propósitos formales básicos definidos por los valores de la certeza jurídica y la eficacia» (Alexy, 2008, pp. 90).

6 Una restricción institucional complementaria a la idea de proceso como juego único es la prohibición de mutatio libellis (artículo 400 de la Ley 1/2010, de 7 de enero, de Enjuiciamiento Civil) que impide la alteración del objeto del proceso durante el curso del juicio. En efecto, cada juez que participa en un proceso tendrá una única posibilidad de decisión (idea del proceso como juego único) y alternativas limitadas de decisión (no pudiendo complementar o adicionar con su sentencia el objeto del proceso). Sobre esta prohibición, véase Damián, J., La Nueva Ley de Enjuiciamiento Civil, en Valentín Cortés y Juan Montero Aroca (dirs.), Tecnos, tomo II, Madrid, 2010, p. 55.

7 Norma que señala: «Los Jueces y Tribunales tienen el deber inexcusable de resolver en todo caso los asuntos que conozcan, ateniéndose al sistema de fuentes establecido».

8 Véase STS 532/2013 de 19.09.2013, considerando $7^{\circ}$. 
Lo anterior, entre otras herramientas, se cumple por medio de las decisiones judiciales que pueden acceder a las pretensiones que se hacen valer en un proceso civil. Esto es, condenando a una determinada prestación de dar, hacer o no hacer; declarando ciertos derechos, o bien, constituyendo nuevas situaciones jurídicas. ${ }^{9}$

Las características anteriores asociadas al ejercicio jurisdiccional (fundamentalmente la idea del proceso como un juego no repetitivo), han conducido a que se sostenga la imposibilidad de aplicar criterios de eficiencia como factores de decisión judicial. Se ha indicado que el proceso civil no entregaría los espacios de decisión suficientes para que tales criterios puedan ser aplicados por un juez, más aún si el proceso le entrega información incompleta (Kornhauser, 1980, p. 606). Por lo mismo quisiera explorar consideraciones que favorecen la posibilidad del ejercicio jurisdiccional como una actividad que tienda a la seguridad jurídica a pesar que ello surja de un cúmulo imperfecto de información.

Para ello daremos una razón para reducir los efectos negativos de los comportamientos estratégicos de las partes que subyacen dentro del juego procesal (a esta razón la denominaremos «juego único procesal como vía de reducción de divergencia entre las partes»). Esa razón conduce a que al momento de la decisión, el juez posea la información suficiente para resolver asuntos que surjan en sub-conjuntos normativos donde opera la eficiencia. ${ }^{10}$

9 Sobre la clasificación de las acciones entre declarativas, de condena y constitutiva, véase Toribios, F., «Sentencias meramente declarativas y sentencias constitutivas», en Fernando Toribios (ed.), Comentarios a la Ley de Enjuiciamiento Civil, Lex Nova, Valladolid, 2012, p. 875; Puppio, V., Teoría General del Proceso, Universidad Católica Andrés Bello, Caracas, 2008, pp. 150-151; CALAZA, S., «La cobertura actual de la cosa juzgada», Revista Jurídica de la Universidad Autónoma de Madrid, Vol. 2, núm. 20, 2009, pp. 70-71.

$10 \mathrm{Se}$ ha sostenido que ciertos sub-conjuntos normativos aplican judicialmente criterios de efíciencia. Ello ocurriría en (i) Libre Competencia, véase PAz Ares, J.C., «La economía política como jurisprudencia racional. Aproximación a la Teoría económica del Derecho», Anuario de Derecho Civil, Vol. XXIV, 1981, pp. 609-610; TAPIA, J., y CORDERO, L., «La revisión judicial de las decisiones regulatorias: Una mirada institucional», Revista de Estudios Públicos, Vol. 139, 2015, p. 53, y (ii) Derecho concursal, véase GuRreA, A., «La incomprensible preferencia del convenio a la liquidación como solución del concurso de acreedores», en Ángel Rojo, Jesús Quijano, y Ana Campuzano (dirs.), La liquidación de la masa activa. VI Congreso Español del Derecho de la Insolvencia, Thomson Reuters-Civitas, Cizur-Menor, 2014, pp. 838; Rojo, A., «Notas para la reforma de la legislación concursal», Revista de Derecho Mercantil, Vol. 138, 1975, pp. 527-528; CABRILlo, F., Quiebra y 


\section{El juicio único procesal como vía para reducir divergencias entre las partes}

Al analizar esta razón expondremos los motivos por el cual el proceso judicial es una solución a juegos estratégicos que pueden afectar a las partes y que de acuerdo a la teoría económica conducen a soluciones indeseadas. El proceso como juego único respaldado por el ejercicio coercitivo e imperativo en la imposición de juicios de valor, soluciona algunos inconvenientes generados por conductas estratégicas de las partes. El carácter de juego único procesal es una vía de solución imperativa en aquellos juegos estratégicos que impiden soluciones (y por tanto, el proceso ayuda reducir las divergencias entre las partes), debido a que dificultan la formación de creencias racionales respecto del otro jugador.

Las partes al saber que tienen un solo juego para acreditar sus pretensiones o defensas, tienen la carga de que sus alegaciones de pretensión o defensas sean expresadas sinceramente, a lo menos, en un último momento. Lo anterior, porque luego de ese momento precluirá la posibilidad de hacer valer tales alegaciones o defensas ${ }^{11}$. Ello permite que las partes se formen creencias racionales acerca de las preferencias e informaciones que posee la otra parte. El proceso conduce a que el nivel probatorio que las partes deben realizar para acreditar sus pretensiones y defensas se consiga debido a que los incentivos están puestos en beneficio de sus propias expectativas de ganancia y pérdidas, debiendo cada una de ellas interiorizar los costos que supone su deseo de ganar. Asimismo, el proceso también conduce a que las partes planteen hasta cierto momento las alegaciones que reflejan sus preferencias e información en el juicio, ya que de nada les sirve guardarse esas alegaciones y pruebas una vez que hayan vencido los plazos para hacerlo.

El juez al operar como un dictador en el juego, esto es, como alguien que lo soluciona por una decisión imperativa, tomará su determinación sobre algunas

liquidación de empresas, Unión Editorial, Madrid, 1989, pp. 39-73.

11 La preclusión es la sanción procesal por no haber valer los derechos, facultades y prerrogativas en el marco de un proceso en el plazo o oportunidad establecido por el orden consecutivo legal. Para mayor información, véase Gandulfo, E., «Sobre preclusiones procesales en el derecho chileno en tiempo de reformas. Ensayo de una teoría general desde un enfoque valorativo jurídico», Ius et Praxis, Vol.15, núm. 1, 2009, pp. 121-189. 
de las atribuciones de ganadores-perdedores que hayan planteado las partes en el juicio $^{12}$. Al respecto, supongamos que cada parte ha sustentado una alternativa de solución (alternativa A para el demandante, y alternativa B para el demandado) y que el juez no puede indagar otras posibles soluciones ${ }^{13}$. En tal caso, lo que plantea la razón del juego único procesal como vía de reducción de divergencias entre las partes, es que ambas alternativas (A y B) serán completas, desde el momento en que el proceso impida alterar su formulación. Entendemos que una alternativa es completa, cuando incluye la argumentación de todos los factores relevantes para obtener un resultado jurisdiccional favorable a la posición de la parte respectiva. La fuente donde las partes encuentran los factores relevantes a ser argumentados, normalmente se ubica en una norma sustancia ${ }^{14}$. Por su parte, entendemos que el proceso impide la alteración de la formulación de esas alternativas, cuando establece un regla que impide que la argumentación de esos factores sea modificada a partir de cierto momento. La fuente de la regla que

$12 \mathrm{Si}$ entendemos que la decisión judicial genera un binomio de ganadores-perdedores, tendremos que aceptar que ello se origina en una elección previa entre diversas situaciones sociales que pueden estar en juego al momento de la decisión. Por lo mismo, podemos diferenciar la atribución inmediata de ganadores-perdedores (que se alcanza por medio de la decisión judicial), y la atribución mediata de ganadores-perdedores (que viene dada por la elección de aquella opción disponible para el juez a efectos de adoptar la decisión judicial). La atribución inmediata es única y pública, ya que consta en un acto jurídico procesal perfectamente identificable (resolución que contiene la decisión), y además, dicho acto será de conocimiento de todos los sujetos, ya que normalmente los actos de los tribunales son públicos (véase artículos 138 y 141 de la Ley 1/2010, de 7 de enero, de Enjuiciamiento Civil). En cambio, la atribución mediata tiene como característica ser múltiple y normalmente secreta, ya que, existen muchas posibles elecciones a ser consideradas por el tribunal para fundar una decisión, y además, como normalmente la elección aceptada es aquella que se contiene en la sentencia el resto de las otras elecciones posibles de atribución mediata normalmente serán desconocidas para alguien distinto del juez (véase artículo 139 de la Ley 1/2010, de 7 de enero, de Enjuiciamiento Civil).

13 Como supondría una extensión restrictiva del principio iura novit curiae, en cuanto el juez no podría fundar su decisión en una calificación jurídica diversa de aquella hecha valer por las partes. Como aclaración se debe señalar que esto es solamente una suposición para efectos del ejemplo, y no pretende ser una descripción del estado normativo en el Derecho procesal español o en otra legislación positiva. Sobre una interpretación extensiva o restrictiva de ese principio, véase Romero, A., «La congruencia de la sentencia», Revista Chilena de Derecho, Vol. 25, 1998, pp. 447-451.

14 Veremos en el juego de la reivindicación que desarrollaremos más adelante, que las normas que regulan el conflicto de adquisición de dominio de bienes por prescripción poseen un carácter marcadamente sustantivo. Así ocurre con la regulación de la prescripción del dominio y demás derechos reales (contenidas en los artículos 1940 a 1960 del Código Civil español), así como con las normas sobre reivindicación (artículos 348 y 1963 del Código Civil español). 
impide modificar los factores relevantes de la argumentación, normalmente se ubica en una norma adjetiva ${ }^{15}$.

De esta forma, en la medida que el proceso como juego único conduce a la formación de alternativas completas, no susceptibles de modificación desde cierto momento, entonces, se obtendrán creencias racionales entre las partes sobre las preferencias e información que sustentan tales alternativas.

Así, el proceso como juego único favorece que las alternativas queden establecidas tempranamente en el proceso. Y si bien, esas alternativas suponen intereses opuestos en un juego no colaborativo, existen los incentivos para la formulación adecuada de las alternativas que sustentan tales intereses (en la expectativa que la formulación completa de las alternativas solo favorecerá y beneficiará a la parte que la sostiene). De esta forma, desde cierto momento en el proceso, las partes pueden actuar sobre la base de un conocimiento completo respecto de las preferencias, creencias e información que conforman las alternativas de la contraria. Por esta razón el proceso ofrece a las partes que tienen intereses contrapuestos (y en la medida que tales intereses sean relevantes para el Derecho), una solución a posiciones estratégicas que pueden surgir en un escenario alternativo ${ }^{16}$, por ejemplo, el de una negociación. En tal escenario no existen reglas para la conformación de alternativas completas y definitivas, lo que dificulta que las partes alcancen acuerdos mutuamente beneficiosos. Para clarificar tales ideas, recurriremos a un ejemplo de un juego cooperativo finito sin reglas y a un juego procesal único con reglas.

15 Como ocurre en el proceso civil ordinario español de acuerdo a la regulación de los artículos 400, $401 \mathrm{~N}^{\circ} 2$ , y 412 de la Ley 1/2010, de 7 de enero, de Enjuiciamiento Civil.

16 Un reciente estudio indaga acerca de las condiciones en que se conducen los comportamientos de los litigantes en un contexto de litigación, véase Pecorino, P., y Van Boening, M., «Bargaing with Asymmetric Dispute Costs», Review of Law \& Economics, Vol. 10, núm. 1, 2014, pp. 31-58. 


\section{II.1 Juego cooperativo finito sin reglas (cooperar 0 apropiar)}

En primer lugar, mencionaremos un juego sin proceso, en donde las partes pueden cooperar en un número finitos de movimientos, sin que exista regulación legal que las rija. Las partes serán $\mathrm{X}$ e $\mathrm{Y}$, y el juego supone que $\mathrm{X}$ invierte $\$ 1$ en un proceso colaborativo con $\mathrm{Y}$, quien de cooperar puede cuadriplicar la inversión inicial de $X(\$ 1)$ a $(\$ 2+\$ 2=4)$, o bien, puede apropiarse de ese monto, en cuyo caso no existirá más colaboración entre las partes y solamente $\mathrm{X}$, sufrirá la pérdida del valor inicialmente invertido. Una vez que $\mathrm{Y}$ colabora, le corresponde colaborar a $\mathrm{X}$, quien tiene las mismas opciones de $\mathrm{Y}$, y en caso que $\mathrm{X}$ decida cooperar, entonces, Y tendrá una última opción de apropiación o colaboración. Lo anterior, se representa como juego 1, en donde las estrategias pueden ser apropiar (A) o colaborar (C). A esas estrategias se debe sumar la estrategia de X de no colaborar o no invertir (-C). El primer número representa la recompensa que recibe $\mathrm{X}$, y el segundo número representa la recompensa que recibe $\mathrm{Y}$ :

\section{Juego 1: Cooperar o Apropiar}

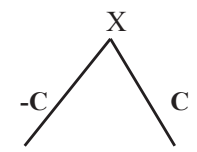

$(\mathbf{0 , 0 )}$
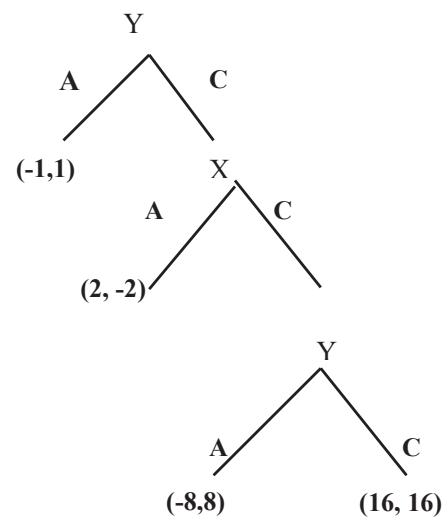
Podemos apreciar que el juego posee los siguientes movimientos:

- Comienza con la deliberación de X de colaborar (C) o no colaborar o invertir (-C) la suma de $\$ 1$ con Y:

Si X decide no colaborar, las recompensas para ambos jugadores serán $(0,0)$ ya que no habrá juego, o

Si X decide invertir o colaborar (C), el juego continúa en el movimiento siguiente.

- Luego Y tiene las alternativas de:

Apropiarse de la inversión de X (A), en cuyo caso las recompensas serán $(-1,1)$, debido a que solamente $\mathrm{Y}$, recibe una ganancia de $\$ 1$. En cambio, $X$, tiene una pérdida igual a su inversión inicial $(\$-1)$, o

Cooperar con X (C), y cuadruplicar el monto de la inversión inicial, generando para cada uno recompensas de $(2,2)$, que significan que tanto X como Y obtienen \$2. En este caso, el juego continúa, en el movimiento siguiente.

- Posteriormente, le corresponde el turno a X, que debe elegir si apropiarse (A) de la ganancia producida por la cooperación de $\mathrm{Y}(2,-2)$, o bien, cuadruplicar la ganancia producida, en cuyo caso ambos obtienen $(8,8)$. Lo mismo sucede con Y, que debe elegir si apropiarse (A) de la ganancia producida por la cooperación de X $(-8,8)$, o bien, cuadruplicar la ganancia producida, en cuyo caso ambos obtienen $(16,16)$. El juego termina en los nodos terminales que se reflejan con las recompensas en negritas.

La pregunta que surge en este caso es si habrá o no habrá cooperación. Ello depende de si las partes son capaces de formarse una creencia precisa respecto de lo que hará el otro jugador. Lo anterior, depende de la información que tengan sobre la situación y las preferencias del otro (Elster, 1997, p.54). De esta forma, si tanto X como Y, no tienen información acerca de la honorabilidad del otro jugador, entonces, puede ser perfectamente racional que no exista juego. La falta de claridad respecto de que el otro jugador es honorable, genera el 
riesgo de apropiación. Y si esa posibilidad se conoce desde un inicio, entonces por regresión, $\mathrm{X}$ decidirá no invertir, o Y no cooperará, en términos tales, que también por regresión, $X$ decidirá no invertir al comienzo del juego. Ello ocurrirá porque la solución de juegos dinámicos como el señalado, donde la decisión de uno de los jugadores supone el conocimiento de la decisión previa del otro, es la «Inducción hacia Atrás» (Binmore, 2011, pp. 79-82): si X prevé que, Y no cooperará, por no estar seguro que es un ser honorable, entonces, por inducción él no invertirá al inicio del juego.

La posibilidad del comportamiento estratégico de las partes, en el ejemplo de un juego cooperativo finito sin reglas, impide que el juego exista. Ello a pesar que el juego sea socialmente deseable, ya que se mejorará la riqueza social 32 veces, desde $\$ 1$, hasta $\$ 32(16+16=32)$. La razón la debemos encontrar en que un juego sin reglas no posee los instrumentos necesarios para generar creencias precisas respecto de las preferencias del otro. En otras palabras, no existen herramientas para eliminar la posibilidad de comportamientos estratégicos; por tanto, es difícil que se eliminen divergencias.

\section{II.2 Juego procesal único con reglas (juego de reivindicación)}

La cuestión que emerge es ¿Qué sucede con el juego procesalúnico? Para responder esa pregunta, examinaremos un juego procesal con reglas, que por esencia es no cooperativo. Sin embargo, en tal juego se permite alcanzar una mejora en la formación de las creencias de los sujetos respecto de las preferencias y creencias de su contraparte. El proceso judicial, por tanto, es un contexto de decisión social que trae consigo la generación de alternativas completas y definitivas, implicando ello una mejora para enfrentar comportamientos estratégicos.

Supongamos que en un sistema jurídico cualquiera un potencial demandante $\mathrm{X}$, dice ser dueño de un inmueble que está poseyendo Y. La situación es compleja debido a que Y, también dice ser dueño del inmueble. Supongamos que de acuerdo a una legislación hipotética, ganará el proceso la parte que posee actualmente el bien siempre que alegue la prescripción adquisitiva 
correspondiente. Supongamos que el único plazo de prescripción de bienes inmuebles es de 10 años de posesión ininterrumpida (Y posee el bien durante un plazo de 12 años). De esta forma tal parte se encuentra en condiciones de poder alegar la prescripción adquisitiva del inmueble. Finalmente, supongamos que para poder hacer valer esa prescripción, Y, debe alegarla expresamente al momento de contestar la demanda. En este caso, el juego se debería desarrolla de la siguiente forma:

\section{Juego 2: El caso de la reivindicación}

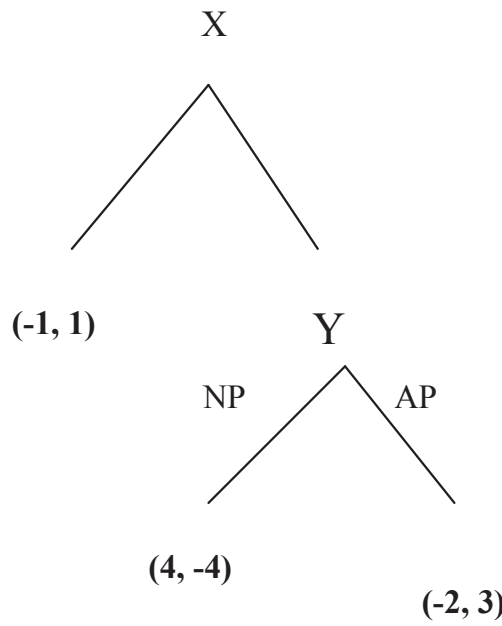

En el juego anterior, las retribuciones de cada jugador se muestran entre paréntesis, correspondiendo el primer número a la recompensa para $\mathrm{X}$ y el segundo número a la recompensa para $\mathrm{Y}$. Las estrategias para $\mathrm{X}$ son demandar o no demandar. Solamente para el caso que demande, se abren las estrategias del demandado, las que son: no alegar prescripción (NP), o bien, alegar prescripción (AP). El juego finaliza en los nodos terminales que se reflejan con las recompensas en negritas.

- El juego comienza cuando X ejerce su acción contra Y. Para el caso que $\mathrm{X}$ no demande, entonces, las recompensas son $(-1,1)$ que reflejan el estado actual en que se encuentran los sujetos, esto es, con X sin tener la 
posesión de la cosa (-1), e Y manteniéndola (1).

- Una vez que el demandante ejerce su acción, Y tendrá dos opciones.

La primera es no alegar la prescripción adquisitiva en la contestación de la demanda (NP), en cuyo caso las recompensas serán $(4,-4)$. Esas recompensan reflejan que $\mathrm{X}$ ganará el juicio si logra acreditar que es dueño, obteniendo (4), que representa el valor que $X$, asocia al tener claridad que $\mathrm{Y}$, no alegó la prescripción que suponía podía alegar para discutirle su pretensión. Por su parte, Y, obtendrá (- 4), que representa el costo que para él supone perder el juicio.

La segunda opción es alegar la prescripción adquisitiva en la contestación de la demanda (AP). En este caso, las recompensas serán $(-2,3)$, que representan el valor del costo que soporta el demandante $\mathrm{X}(-2)$ por haber iniciado y perder el juicio; así como, el valor que obtiene el demandado Y (3) por haber ganado, y obtener una sentencia que refuerce su posesión sobre la cosa.

Este ejemplo nos indica que la concurrencia de las reglas sustanciales (que regulan la reivindicación y la prescripción adquisitiva) con reglas procesales (que regula el momento en que deben formularse las alegaciones de pretensión o defensas de las partes) en el marco de un juicio único conducen a que las partes vayan manifestando sus alternativas de pretensiones y defensas de manera clara. En el ejemplo, las expectativas de ganancias y pérdidas de las partes dependían de si el demandado Y, alegaba la prescripción adquisitiva en un momento determinado (contestación de la demanda). De la existencia o no de esa alegación dependían los costos que las partes debían asumir en el juicio, derivados de una mayor litigación (en el caso que existiera tal alegación) o de una menor litigación (en caso que no existiera esa alegación). Ello nos permite concluir que el proceso permite la formación de creencias precisas respecto de lo que harán sus contrapartes, incluso, cuando no se encuentran cooperando, como ocurre en el contexto de un litigio. Así, se produce el efecto de reducir los comportamientos estratégicos, o por lo menos, poner un momento final en que esos comportamientos estratégicos pueden develarse. 


\section{II.3 El ejemplo del juicio verbal en el Derecho procesal civil español}

Antes de finalizar me gustaría hacer presente algunas breves consideraciones acerca de la reducción de divergencias entre las partes por medio de reglas procesales a través del ejemplo del juicio verbal en el Derecho procesal civil español. La última reforma respecto de tal procedimiento nos permite destacar un aspecto resaltable y un aspecto susceptible de mejora en relación a la utilización de reglas procesales con miras a evitar comportamientos estratégicos.

Comenzando con lo valorable desde una perspectiva de eficiencia y de debido proceso, debemos referir que la reforma llevada a cabo por la Ley $42 / 2015$, de 5 de octubre, estableció que la contestación de la demanda de juicio verbal debe ser presentada por escrito antes de la vista de la causa. De esta forma, una vez que la contestación se presenta, se citará a tal vista ${ }^{17}$. Con anterioridad, la contestación se realizaba en la audiencia misma ${ }^{18}$, de forma que se generaban dos externalidades negativas para el demandante: (i) Una externalidad negativa de debido proceso referente a que el demandante solamente conocía el contenido de las excepciones y defensas en la misma audiencia en que debía rendir la prueba. Ello generaba menor tiempo de reacción y menores posibilidades de bilateralidad de audiencia, ya que solamente el demandado poseía todo el tiempo intermedio entre la notificación de la demanda y la vista de la causa para preparar su estrategia probatoria, y (ii) Una externalidad negativa de eficiencia, asociada al costo privado soportado por el demandante, en cuanto a carecer oportunamente de un conocimiento de las preferencias e información que sustentan las excepciones y defensas del demandado. Ese costo privado podría ser también un costo social, si es que el mayor espacio para la conducta estratégica del demandado conducía a

17 Artículo 440.1 de la Ley 1/2010, de 7 de enero, de Enjuiciamiento Civil.

18 En la redacción del artículo 440.1 de la Ley 1/2010, de 7 de enero, de Enjuiciamiento Civil, luego de la reforma contenida en la Ley 5/2012, de 6 de julio, de mediación en asuntos civiles y mercantiles, tal norma poseía la siguiente redacción: «El secretario judicial, examinada la demanda, la admitirá o dará cuenta de ella al tribunal para que resuelva lo que proceda conforme a lo previsto en el artículo 404. Admitida la demanda, el secretario judicial citará a las partes para la celebración de vista en el día y hora que a tal efecto señale, debiendo mediar diez días, al menos, desde el siguiente a la citación y sin que puedan exceder de veinte». 
una mayor tasa de error ${ }^{19}$.

La reforma del juicio verbal aminora fuertemente tales externalidades. Ambas partes se enfrentarán en la vista de la causa conociendo previamente las acciones y defensas de la contraria. Asimismo, tendrán el mismo tiempo para formular sus peticiones de prueba (mejora de debido proceso). Por otro lado, ninguna de las partes podría sorprender a la contraria haciéndoles asumir un costo de prevención de conductas estratégicas ${ }^{20}$ (mejora de eficiencia). Ambas mejoras ayudan a reducir los espacios de divergencia entre las partes, ya que ellas se enfrentarán en la vista de la causa con un conocimiento cierto de las preferencias e información que sustenta las acciones y defensas de su contraria, así como, también, tendrán cierto conocimiento de los medios de prueba con lo que pretenden acreditar sus argumentos ${ }^{21}$. Otras reglas procesales coadyuvan a alcanzar esa reducción. Me refiero a ciertas reglas que determinan un resultado cierto si suceden determinadas actuaciones o omisiones. Por ejemplo, la decisión desestimatoria o estimatoria de la demanda por la incomparecencia a la vista de la causa $^{22}$, o bien, la restricción de las alegaciones de defensa que para ciertos casos

19 Se ha estimado que un factor que determina la existencia de un mayor o menor costo social de litigar corresponde al error judicial que gatilla bajas reducciones en la disuasión de conductas socialmente óptimas. Por tanto, es posible afirmar que a mayor tasas de error judicial más alta probabilidad de un mayor costo social, véase ShavelL, S., «The social versus the private incentive to bring suit in a costly legal system», Journal Legal Studies, Vol. 11, 1982, p. 336.

20 La realización de conductas estratégicas tiene consecuencias en los costos de prevención que debe asumir la parte contraria ya sea en una negociación o en un proceso judicial. Por tanto, tales conductas estratégicas corresponden a una especie de costo de transacción que reduce un resultado óptimo, véase SCHÄFER, H.B., y Отт., C., The Economics Analysis of Civil Law, Edward Elgar Publishing, Northampton, 2004, pp. 90-91.

21 Por ejemplo, el artículo 440.1 párrafo 4 de la Ley 1/2010, de 7 de enero, de Enjuiciamiento Civil, indica que la citación para la vista informará a las partes «(...) que, en el plazo de los cinco días siguientes a la recepción de la citación, deben indicar las personas que, por no poderlas presentar ellas mismas, han de ser citadas por el secretario judicial a la vista para que declaren en calidad de parte, testigos o peritos». Asimismo, el artículo 441.4 de la Ley 1/2010, de 7 de enero, de Enjuiciamiento Civil, se establece que en el caso de acciones sobre incumplimiento por el comprador de las obligaciones derivadas de los contratos inscritos en el Registro de Venta a Plazo de Bienes Muebles y formalizados en el modelo oficial, admitida la demanda el tribunal ordenará la exhibición de los bienes a su poseedor; lo que favorece un acceso a una fuente de prueba real con anterioridad a la decisión del asunto.

22 Un supuesto de decisión desestimatoria de la demanda sin decisión sobre el fondo ocurre cuando el demandante no asiste a la vista de la causa, siempre que el demandado no alegare interés legítimo en la continuación del proceso para que se dicte sentencia sobre el fondo, de conformidad al artículo 442.1 de la Ley 1/2010, de 7 de 
contempla la ley ${ }^{23}$.

A pesar de valorar positivamente las mejoras de reducción de divergencias entre las partes que se han indicado para el juicio verbal, de todas formas, es posible alcanzar un escenario más óptimo de reducción de esas divergencias, si maximizamos la mejora desde el punto de vista de los niveles de conocimiento de las preferencias e información de la contraria. Me refiero al hecho que las mayores posibilidades de acuerdo (y por tanto, de reducción de divergencias) existirá cuando las partes se encuentren en el máximo estado de conocimiento respecto de las preferencias e información que sustentan las acciones o excepciones de la contraria. Ese nivel se alcanzará una vez vencida la rendición de prueba. En tal momento, se debería contemplar una posibilidad de conciliación o mediación, igual o mayormente intensiva que aquella dispuesta por ley para el comienzo de la vista de la causa ${ }^{24}$. Tal propuesta no satisface completamente la finalidad de evitar el probatorio, reduciendo su utilidad solamente a la posibilidad de evitar el costo social asociado al tiempo de toma de decisión del asunto. De todas formas, esta propuesta resulta en beneficios sociales que no son indiferentes. Para ello consideremos que existe la sensación de una escasa tasas de conciliaciones exitosas en el periodo precedente a la vista de la causa, y asimismo, pudiera no resultar negativo colaborar a reducir el costo de decisión, pudiendo hacerlo.

Por otro lado, la racionalidad detrás de una regla de auto-composición en ese estado del proceso, se encuentra en la misma racionalidad del discovery en el Derecho norteamericano ${ }^{25}$, la que no es otra que forzar acuerdos cuando mayor conocimiento existe del éxito de las pretensiones o defensas de cada una

enero, de Enjuiciamiento Civil. Por su parte, habrá sentencia estimatoria de la demanda cuando el demandado no concurre a la vista en un juicio verbal donde se ejercite una acción que persiga la efectividad de un derecho real inscrito en el Registro de Propiedad frente a quienes se opongan a ello o perturben su ejercicio sin disponer de título inscrito que legitime su oposición o perturbación, de conformidad al artículo 440.2 en relación al número $7^{\circ}$ del apartado 1 del artículo 250 de la Ley 1/2010, de 7 de enero, de Enjuiciamiento Civil.

23 El artículo 444.3 en relación al artículo 250.7 de la Ley 1/2010, de 7 de enero, de Enjuiciamiento Civil.

24 La regulación actual contempla tal posibilidad de conciliación y mediación como una gestión que se desarrolla al momento del comienzo de la vista de la causa (artículos 440.1 y 443.1 de la Ley 1/2010, de 7 de enero, de Enjuiciamiento Civil)

25 Regulación contenida en las reglas 26 a 37 del título V de las Federal Rules of Civil Procedure, e introducidas el año 1938. 
de las partes (Bone, 2014, p. 298; Shavell, 2004, pp. 426-427; Sobel, 1989, pp. 133-159). Incluso, una regulación adecuada de esos medios de composición del conflicto tendría una ventaja adicional en comparación al discovery, ya que en el presente caso una mejora en el sentido indicado será introducida cuando existen pretensiones y defensas ya ejercidas, sin que las partes puedan modificar esas alegaciones. Ese riesgo de modificación estratégica de alegaciones es posible en el discovery porque la revelación de prueba ocurre previo al juicio, existiendo un espacio temporal en que es posible que las partes adecúen sus alegaciones ${ }^{26}$. Así, la hipótesis de mejora de reducción de divergencias debería ser testeada sobre la base de una investigación empírica que considere el momento preferente en que se alcanzan salidas auto-compositivas en el juicio verbal. Si esos acuerdos son alcanzados más comúnmente una vez rendida la prueba, entonces, existirá una razón práctica de eficiencia para promover una reforma que establezca adecuadamente mecanismos de conciliación y mediación en ese momento del proceso $^{27}$.

En suma, hemos podido apreciar que el proceso permite como contexto de decisión social generar información acerca de las preferencias de la contraria. Ello trasunta en que las partes elaborarán al juez alternativas de elección completas y definitivas (atribuciones mediatas de ganadores y perdedores). Esto último, en el marco de un juego procesal único y no repetitivo, reduce las posibilidades de comportamientos estratégicos, ayudando a favorecer una mejor decisión (atribución inmediata de ganadores y perdedores), incluso, en contextos de elección judicial donde la aplicación de la eficiencia hace presuponer una mayor necesidad de información.

26 En sentido similar, y dando cuenta de las dificultades de una revelación sincera de prueba en el marco de un proceso de discovery (lo que origina mayores posibilidades de conductas estratégicas), se pronuncia SHAVELL, S., Foundations of Economic Analysis of Law, The Belknap Press of Harvard University Press, Cambridge, 2004, pp. 427-428.

27 En línea con lo anterior se ha sostenido que la probabilidad de una salida auto-compositiva debería aumentar a medida que el juicio avanza, porque las partes tendrían mayor acceso a información. El único efecto que compensaría esa mayor posibilidad de acuerdo es la reducción del costo incremental del litigio (lo que favorecería privilegiar el juicio al acuerdo). Sin embargo, tal reducción sería relevante en caso que el proceso llegue a una apelación (debido al bajo costo de la apelación, dado que la sentencia resume y concentra el debate de las instancias subsiguientes), y no con anterioridad a que se adopte la decisión en primera instancia, véase Posner, R., El análisis económico del derecho, Fondo de Cultura Económica, México D.F, 1992, pp. 525-526. 
Tal cúmulo de información puede fluir en el proceso de manera más clara en la medida que las alternativas que presenten las partes sean completas y definitivas, tal como se favorece con el entendimiento del proceso como juego procesal único. Todo lo cual permite que el juez cumpla su función pública judicial de resolver el asunto por medio de una atribución inmediata de ganadoresperdedores, atemperando el desconsuelo que algunos pudieran sentir basados en la supuesta imposibilidad del ejercicio jurisdiccional en aquellos sub-conjuntos normativos donde aplica la eficiencia, y en donde, por tanto, se requeriría mayor cúmulo informacional.

\section{Conclusiones}

En este artículo se desarrolla una característica del proceso civil que coadyuva al juez para que pueda resolver en base a consideraciones de eficiencia. Esa característica resulta de elementos básicos del proceso civil, examina desde la perspectiva del análisis económico del derecho. La misma se refiere a la potencialidad de las normas procesales en reducir los efectos negativos de los comportamientos estratégicos de las partes de un proceso civil. Con ayuda de la normativa procesal civil española, realzamos el efecto positivo que poseen las reglas de preclusión a favor de las posibilidades de alcanzar comportamientos colaborativos dentro del proceso. Tales comportamientos reducen los costos de litigación, y son promovidos (con ciertas limitaciones), por reglas procesales.

\section{Bibliografía}

Alexy, R. (2008). El concepto y la naturaleza del derecho. Madrid: Marcial Pons.

Binmore, K. (2011). Teoría de Juegos. Una breve introducción. Madrid: Alianza Editorial.

Bone, R. (2014). , «Discovery». En Pía Tavolari y Álvaro Pérez (Coords.), Derecho Procesal Civil comparado: Homenaje a Rolf Stürner 
(pp.297-317), Santiago: LegalPublishing-Thomson Reuters

CABrillo, F. (1989). Quiebra y liquidación de empresas. Madrid: Unión Editorial.

Calaza, S. (2009). «La cobertura actual de la cosa juzgada». Revista Jurídica de la Universidad Autónoma de Madrid, 20(2), pp. 67-93.

Couture, E. (2004). Fundamentos de Derecho Procesal. Montevideo: Editorial B de F.

Elster, J. (1997). EGOnomics. Barcelona: Gedisa.

GANDUlfo, E. (2009) «Sobre preclusiones procesales en el derecho chileno en tiempo de reformas. Ensayo de una teoría general desde un enfoque valorativo jurídico». Ius et Praxis, 15(1), pp. 121-189.

GurreA, A. (2014). «La incomprensible preferencia del convenio a la liquidación como solución del concurso de acreedores». En Ángel Rojo, Jesús Quijano y Ana Campuzano (Dirs.), La liquidación de la masa activa. VI Congreso Español del Derecho de la Insolvencia (pp. 829-848), España: Thomson Reuters-Civitas.

Kornhauser, L. (1980). «A Guide to the Perplexed Claims of Efficiency in the Law». Hofstra Law Review, 8(3), pp. 591-639.

Kremer, C. (2010). «Los límites de la cosa juzgada en el Derecho de la Unión Europea». Revista de Derecho de la Pontificia Universidad Católica de Valparaíso, XXXV, pp. 189-226.

Marinoni, L.; Pérez-Ragone, Á. y NúÑEz, R. (2010). Fundamentos del Proceso Civil. Hacia una teoría de la adjudicación. Santiago: Abeledo Perrot.

Martínez, P. (2012). «El principio de inexcusabilidad y el derecho de acción desde la perspectiva del Estado Constitucional». Revista Chilena de Derecho, 39(1), pp. 113-147.

PAZ, J. (1981). «La economía política como jurisprudencia racional. Aproximación a la Teoría económica del Derecho». Anuario de Derecho Civil, XXIV, pp. 601-708.

Pecorino, P. y Van Boening, M. (2014). «Bargaing with Asymmetric Dispute Costs». Review of Law \& Economics, 10(1), pp. 31-58. Posner, R. (1992). El análisis económico del derecho. México: Fondo de 
Cultura Económica.

Puppio, V. (2008). Teoría General del Proceso. Caracas: Universidad Católica Andrés Bello.

Romero, A. (1998). «La congruencia de la sentencia». Revista Chilena de Derecho, 25, pp. 447-451.

Rojo, Á. (1975). «Notas para la reforma de la legislación concursal». Revista de Derecho Mercantil, 138, pp. 509-532.

Schäfer, H. у Отт C. (2004). The Economics Analysis of Civil Law.

Northampton: Edward Elgar Publishing.

Shavell, S. (2004). Foundations of Economic Analysis of Law.

Cambridge: The Belknap Press of Harvard University Press.

Shavell, S. (1982). «The social versus the private incentive to bring suit

in a costly legal system». Journal Legal Studies, 11, pp. 333-339.

Sobel, J. (1989). «An analysis of Discovery Rules». Law and

Contemporary Problems, 52(1), pp. 133-159.

TAPIA, J. y CORDERo, L. (2015). «La revisión judicial de las decisiones regulatorias: Una mirada institucional». Revista de Estudios Públicos, 139, pp. 7-65.

TARUFFo, M. (2007). «Algunas consideraciones sobre la relación entre prueba y verdad». En Michelle Taruffo (Ed.), La prueba, artículos y conferencias, Santiago: Editorial Universitaria.

Toribios, F. (2012) «Sentencias meramente declarativas y sentencias constitutivas»». En Fernando Toribios (Ed.), Comentarios a la Ley de Enjuiciamiento Civil, Valladolid: Lex Nova.

Cómo citar este artículo: Ariel, N. (2019). El proceso civil como vía para reducir divergencias entre las partes. Derecho Global. Estudios sobre Derecho y Justicia, 4(11), pp. 45-65. DOI: 10.32870/dgedj.v0i11.218 
